\title{
Farklı yüzey hazırlama yöntemlerinin fissür örtücülerin bağlanma dayanımı üzerine olan etkisi
}

\author{
Gül Tosun', Halenur Onat Altan², Zeynep Göztaş³, Kamil Kahraman', \\ Tuğrul Sarı ${ }^{4}$, Murat Selim Botsalı ${ }^{1}$
}

\section{Selcuk Dental Journal, 2015; 2: 65-70}

\section{Effect of different surface treatments on shear bond strength of fissure sealants}

Background: This in vitro study aimed to evaluate the shear bond strength of a fissure sealant to enamel treated with ER:YAG laser (MSP and QSP mode) and acid etching with / without drying agent.

Methods: Thirty permanent human molars were used in this study. The roots sectioned $2 \mathrm{~mm}$ coronal to the cementoenamel junction. The crowns were mesiodistally sectioned providing 60 halves that were embedded in acrylic resin. The enamel was flattened and a 2 $\mathrm{mm}$ diameter bonding area was demarcated. Ultraseal XT Plus fissure sealant (FS) was applied in all groups. Specimens were randomly assigned to six groups $(n=10)$; G1: $37 \%$ phosphoric acid + Prima Dry + FS, G2: 37\% phosphoric acid + FS, G3: Er:YAG (MSP mode) + Prima Dry + FS; G4: Er:YAG (MSP mode) + FS; G5: Er:YAG (QSP mode) + Prima Dry + FS; G6: Er:YAG (QSP mode) + FSFS. After 24 hours storage in distilled water, shear bond strength of samples were tested in a universal testing machine. Statistical analysis using Kruskal-Wallis and MannWhitney $U$ test was used to compare the respective groups.

Results: The SBS results (MPa) were the following: G1: 11.33, G2: 9.76, G3: 8.65, G4: 7.72, G5: 4.49, G6: 2.73. There were significant differences amongs the groups ( $p<0.05)$.

Conclusion: The acid etching surface application showed better performance than laser surface treatment in both MSP and QSP mode. Drying agent may be used for enamel surface prior to sealant application.

\section{KEY WORDS}

Acid, fissure sealant, laser QSP
Başvuru Tarihi: 07 Mayıs 2015 Yayına Kabul Tarihi: 14 Temmuz 2015

Modern diş hekimliğinde posterior süt ve daimi dişlerin okluzal yüzeylerinde çukurcuk ve fissürlere bağlı olarak oluşan diş çürüğünün riskini azaltmada, koruyucu uygulamalar, konservatif yaklaşımlar önem arzetmektedir (Splieth ve ark 2007).

Buonocore (1955) tarafından rezin materyallerin retansiyonunun artırıması ve marjinal bütünlüğün sağlanması amacıyla minede fosforik asit kullanılması, fissür örtücülerin gelişiminin başlangıcı olmuştur.

Mine yüzeyininin fosforik asit ile pürüzlendirme işlemi geleneksel yöntem olarak kabul edilmektedir. Fosforik asit hem yüzeydeki artıkları uzaklaştırmakta hem de reçine esaslı örtücü materyalin akacağı mikroporöz bir alan oluşturmaktadır (Waggoner ve Siegal 1996, Koch ve ark 2001). Ancak fosforik asit kullanılmasının ardından yıkama işlemi gerektirmesi ve ardından hoş olmayan tat bırakması çocuk hastalarda olumsuz davranışlara neden olabilir. $\mathrm{Bu}$ nedenle fissür örtücülerin retansiyonunu sağlamak için işlem sırasında izolasyon ya da yıkama gerektirmeyen ve teknik hassasiyeti daha az olan pürüzlendirme yöntemleri geliştirilmiştir (Weintraub 1989).

\footnotetext{
* 101. FDI kongresi, 28-31 Ağustos 2013, İstanbul-Türkiye

${ }^{1}$ Selçuk Üniversitesi Diş Hekimliği Fakültesi Pedodonti Anabilim Dalı, Konya, Türkiye

2 Mustafa Kemal Üniversitesi Diş Hekimliği Fakültesi Pedodonti Anabilim Dalı, Hatay, Türkiye

3 Gazi Üniversitesi Diş Hekimliği Fakültesi Pedodonti Anabilim Dalı, Ankara, Türkiye

${ }^{4}$ Bezmialem Vakıf Üniversitesi Diş Hekimliği Fakültesi Protetik Diş Tedavisi Anabilim Dalı, İstanbul, Türkiye
} 
Son yıllarda kullanımı giderek yaygınlaşan lazer uygulamalarının mine yüzeyinin pürüzlendirilmesi amacıyla kullanımlarında artış olduğu gözlenmektedir. Geçmişte lazer ile pürüzlendirme Nd:YAG ve $\mathrm{CO} 2$ lazer tipleri kullanılabilmekteyken, günümüzde mine dokusunun pürüzlendirmesinde erbium lazerler tercih edilmektedir. Er-YAG lazer (2.94-mm dalga boyu) diş dokusundaki su (3.0mm dalga boyu) ve hidroksiapatit ( $2.8 \mathrm{~mm}$ dalga boyu) tarafından yüksek oranda emilebilmektedir. Bu sayede mine ve dentin dokusunun uzaklaştırımasında etkili olmaktadırlar (Mironow 2012).

Lazer ile yüzey pürüzlendirme işlemlerinde atı̧̧ süresi önemli bir faktördür. Yeni geliştirilen Variable Square Pulse (Fotona, Ljubljana, Slovenia) teknolojisi sayesinde atış süresinin ve atım genişliğinin elektronik olarak kontrolü gerçekleştirilebilmektedir. $\mathrm{Bu}$ teknoloji ile beraber atış süreleri; (50 $\mu \mathrm{s}, 100$ $\mu \mathrm{s}, 300 \mu \mathrm{s}, 600 \mu \mathrm{s}, 1000 \mu \mathrm{s}$ ) ayarlanabilmektedir. Kısa atışlarda yüksek enerji kullanılması; ISı oluşumu sonucu oluşan enerji kaybını en aza indirmektedir. Bunun sonucunda çok etkin bir ablasyon etkinliği gözlenmekte fakat dokularda belirgin bir ISI artışı gözlenmemektedir (Grgurevic ve ark 2005).

Yeni geliştirilen Er -YAG lazer QSP (Quantum-square pulse) modunun kullanımında her atış, birbirini ideal hızda takip eden birkaç küçük atışa bölünmektedir $\mathrm{Bu}$ yolla lazer ışınının abszorpsiyonu ve saçılmasının önüne geçilmekte ve dokular üzerine istenmeyen termal etkiler azalmaktadır (Lukac ve ark 2012).

Dental dokulara bağlantıyı artırmak için üretilmiş materyallerden biriside kurutma ajanlarıdır. Kurutma ajanları; mine yüzeyinin asitle pürüzlendirilmesi ve sonrasında yıkama işlemini takiben kullanılan, içerdiği etil alkol vasıtasıyla artık nemin uzaklaştırımasına yardımcı olan ve bu sayede rezin infiltrasyonunu kolaylaştıran sistemler olarak bilinmektedir. Bunun sonucunda yüzeyler arası pöröziteyi ve adeziv defektleri azalttığı ve bağlanma dayanımı arttırdığı iddia edilmektedir (Boksman ve Carson 1998, Adams ve ark 2000).

$\mathrm{Bu}$ in vitro çalışmada Er-YAG lazer (QSP ve MSPmedium-short pulse- mod) ve asit ile pürüzlendirme yöntemlerinin kurutma ajanı ile birlikte/ birlikte olmaksızın fissür örtücülerin mineye bağlanma kuvvetleri üzerine etkilerini karşılaştırmak amaçlanmıştır.

$\mathrm{Bu}$ çalışmanın hipotezi Er:YAG lazer QSP ve MSP modu kullanımının fissür örtücülerin mineye bağlantısını artıracağı üzerine kurulmuştur.

\section{GEREC ve YÖNTEM}

Çalışmada 30 adet çürüksüz daimi üçüncü molar diş kullanıldı. Dişler pomza ile temizlenip yıkandı ve deney yapılana kadar distile su içinde saklandı. Deney aşamasında dişler mine-sement sınırının $2 \mathrm{~mm}$ üstünden kesildi ve kökler uzaklaştıııldı. Her diş meziodistal olarak ikiye ayrıldı. Elde edilen 60 yarım dişin kuronal parçaları bukkal yüzeyleri dışarıda kalacak şekilde otopolimerizan akrilik reçine içine gömüldü.

Açıkta kalan diş yüzeyleri su altında 400 gritlik zımpara kağıdı ile düzleştirilerek bağlantı için uygun hale getirildi.

Mine yüzeyinin hazırlanmasında Er:YAG lazer QSP modu, Er:YAG lazer MSP modu, \%37'lik fosforik asit gurubu; Prima Dry ile birlikte veya Prima Dry olmaksızın uygulandı. Fissür örtücü materyali olarak Ultraseal XT plus (Ultradent Products, INC,USA) (Tablo 1) kullanıldı. Örnekler 10'ar dişten oluşan 6 gruba ayrild:

G1: \% 37 fosforik asit + Prima Dry + FÖ (Fissür Örtücü- Ultraseal XT plus)

G2: \% 37 fosforik asit +FÖ

G3: Er:YAG (MSP modu) + Prima Dry + FÖ

G4: Er:YAG (MSP modu) + FÖ

G5: Er:YAG (QSP modu) + Prima Dry + FÖ

G6: Er:YAG (QSP modu) + FÖ

Tablo 1.

\section{Çalışmada kullanılan materyaller ve içerikleri}

\begin{tabular}{lll} 
Fissür örtücü & $\begin{array}{l}\text { UltraSeal XT Plus } \\
\text { (Ultradent, South Jordan, UT) }\end{array}$ & $\begin{array}{l}\text { Diurethane dimethacrylate, } \\
\text { bis-glycidylmethacrylate, } \\
\text { photoinitiator, filler 58\% }\end{array}$ \\
Kurutma ajanı & $\begin{array}{l}\text { Prima dry } \\
\text { (Ultradent, South Jordan, UT) }\end{array}$ & $\begin{array}{l}99 \% \text { organic solvents and } \\
\text { (Uimer }\end{array}$ \\
\hline
\end{tabular}

Lazer ile pürüzlendirme işlemi için kısa atımlı $2.94 \mu \mathrm{m}$ dalga boyunda Er:YAG lazer (Fidelis Plusll, Fotona Medical Lasers, Ljubljana, Slovenia) QSP modu (1.2 watts, $10 \mathrm{~Hz}, 24 \mathrm{~J} / \mathrm{cm}^{2}$ ) ve MSP modu (1.2 watts, 10 $\mathrm{Hz}, 24 \mathrm{~J} / \mathrm{cm}^{2}$ ) kullanıldı. Pürüzlendirme üretici firmanın önerileri doğrultusunda kontakt modunda, su soğutması altında $(50 \mathrm{ml} / \mathrm{dk})$ gerçekleştirildi.

Kimyasal pürüzlendirme işlemi için \%37'lik ortofosforik asit jel (Scotchbond, 3M ESPE, USA) 20 sn süresince mine yüzeyine uygulandı, $20 \mathrm{sn}$. su ile yıkandı ve $10 \mathrm{sn}$. basınçlı hava spreyi ile kurutuldu.

Fissür örtücüler mine yüzeylerine yerleştirilen iç çapları $3 \mathrm{~mm}$ ve uzunlukları $2 \mathrm{~mm}$ olan silindir kalıplara üretici firmalarının önerileri doğrultusunda 
uygulandı ve 40 sn süre ile polimerize edildi. Kalıplar bistüri ile dikkatli bir şekilde kesilerek uzaklaştırıldı. Hazırlanan örnekler $37^{\circ} \mathrm{C}$ 'de 24 saat distile suda bekletildi. Instron universal cihazına (Shimadzu Autograph AG-IS, Kyoto, Japan) yerleştirilen örneklere makaslama bağlanma dayanımı testi $(1 \mathrm{~mm} /$ dak) uygulandı ve örneklerde elde edilen kırılma değerler Newton cinsinden kaydedildi. MPa'ya aşağıdaki formül kullanılarak dönüştürüldü.

Megapaskal $(\mathrm{MPa})=$ Newton $(\mathrm{N}) /$ bağlantı yüzey alanı $\left(\mathrm{mm}^{2}\right)$

Gruplarda elde edilen değerlerin ortalama ve standart sapma değerleri (MPa) belirlendi; elde edilen bulguların istatistiksel olarak karşılaştırılmalarında Kruskal-Wallis ve Mann-Whitney U test kullanıldı. Güven aralığı $p<0,05$ olarak kabul edildi.

\section{BULGULAR}

Gruplara ait elde edilen bağlanma dayanım değerleri ve standart sapmaları Tablo 2'de gösterilmiştir. İstatistiksel analize göre çalışmadaki deney gruplarının bağlanma dayanım değerleri arasında anlamlı fark bulunmuştur $(p=0.000)$.

Tablo 2.

\section{Fissür örtücülerin bağlanma dayanımları}

\begin{tabular}{|c|c|c|c|}
\hline Gruplar & $\begin{array}{c}\text { Bağlanma } \\
\text { dayanımı } \\
\text { Ort+SS }\end{array}$ & $\begin{array}{l}\text { Maksimum } \\
\text { (MPa) }\end{array}$ & $\begin{array}{l}\text { Minimum } \\
\text { (MPa) }\end{array}$ \\
\hline$\% 37$ fosforik asit + Prima Dry + FÖ & $11,33 \pm 2,59^{\mathbf{a}}$ & 15,58 & 6,5 \\
\hline$\% 37$ fosforik asit +FÖ & $9,76 \pm 3,37^{\mathbf{a}}$ & 16,11 & 4,42 \\
\hline Er:YAG (MSP modu) + Prima Dry + FÖ & $8,65 \pm 3,10^{\mathbf{b}}$ & 14,34 & 5,99 \\
\hline Er:YAG (MSP modu) + FÖ & $7,72 \pm 3,21^{\mathbf{b}}$ & 13,16 & 4,04 \\
\hline Er:YAG (QSP modu) + Prima Dry + FÖ & $4,49 \pm 0,89^{c}$ & 6,63 & 3,49 \\
\hline Er:YAG (QSP modu) + FÖ & $5,78 \pm 2,73^{\text {cb }}$ & 12,15 & 2,45 \\
\hline
\end{tabular}

Aynı harfler arasında istatistiksel olarak anlamlı farklılık yoktur, $(p<0,05)$

Ortalama bağlanma dayanımı değeri en yüksek Fosforik asit + Prima Dry + FÖ $(11,33 \pm 2.59)$ grubunda; en düşük değer Er:YAG lazer QSP modu + Prima Dry + FÖ $(4.49 \pm 0.89)$ grubunda saptandı.

\%37 Fosforik asit + Prima Dry + FÖ ve \%37 Fosforik asit + FÖ grupları arasında bağlanma dayanımı açısından istatistiksel olarak anlamlı bir fark bulunmadı ( $p>0.05)$.

\%37 Fosforik asit + FÖ ve Er:YAG lazer QSP modu + FÖ grupları arasında bağlanma dayanımı açısından istatistiksel olarak anlamlı bir fark bulunmuştur $(p<0.05)$.
Er:YAG lazer MSP modu + Prima Dry + FÖ ve Er:YAG lazer MSP modu + FÖ grupları arasında bağlanma dayanımı açısından istatistiksel olarak anlamlı bir farklılık $(p>0.05)$ bulunmamıştır.

Er:YAG lazer MSP modu + Prima Dry + FÖ ve Er:YAG lazer QSP modu + Prima Dry + FÖ grupları arasında bağlanma dayanımı açısından istatistiksel olarak anlamlı bir fark bulunmuştur $(p<0.05)$.

Er:YAG lazer MSP modu + FÖ ve Er:YAG lazer QSP modu + FÖ grupları arasında bağlanma dayanımı açısından istatistiksel olarak anlamlı bir fark bulunmamıştır ( $p>0.05)$.

Er:YAG lazer QSP modu + Prima Dry + FÖ ve Er:YAG lazer QSP modu + FÖ grupları arasında bağlanma dayanımı açısından istatistiksel olarak anlamlı bir fark bulunmamıştır $(p>0.05)$.

Prima Dry dikkate alınmaksızın Er:YAG lazer QSP modu, Er:YAG lazer MSP modu ve fosforik asit grupları arasında bağlanma dayanımı açısından istatistiksel olarak anlamlı fark bulunmuştur $(p<0.05)$.

\section{TARTIŞMA}

Fissür örtücülerin diş yüzeyine bağlanmasında asit ile pürüzlendirmeye alternatif olarak çeşitli tiplerde lazer uygulandığı çalışmalar yapılmıştır. Er: YAG lazer uygulanması diş yüzeyinde mikroretantif alanlar oluşturmasıyla adezyon için uygun yüzeyler oluşturur. Bu sayede asit ataklarına karşı mine direncini artırdığı iddia edilmiştir (Gutknecht ve ark 2011). Bu çalışmada Er: YAG lazerin farklı modlarının ve kullanılan kurutucu ajan uygulanmasının fissür örtücünün bağlantısına etkisi araştırılmıştır. Bu çalışmanın hipotezi olan yeni geliştirilen Er:YAG lazerin QSP modunun geleneksel yöntem olan asit uygulamasından daha fazla bağlanma dayanımı oluşturacağı yönündeki kabul doğrulanmamıştır.

Lepri ve ark (2008) asit ile pürüzlendirmede ve Er: YAG lazer ile pürüzlendirme sonrası tükürük kontamine edilen ve edilmeyen mine yüzeyine uygulanan fissür örtücülerin basma dayanımlarını karşılaştırmışlar ve tükrük kontaminasyonuna maruz kalmamış asit ile pürüzlendirilen mine yüzeylerine uygulanan fissür örtücülerin basma dayanımlarının Er:YAG lazer ile pürüzlendirilenlere göre istatistiksel olarak anlamlı derecede yüksek olduğunu bulmuşlardır. 
Güven ve ark. tarafından Er:YAG lazer ve fosforik asit ile mine pürüzlendirmesinin mineye bağlanma kuvvetleri üzerine etkilerinin değerlendirildiği çalışmada, Er:YAG lazer ve Er:YAG lazer + fosforik asit ile pürüzlendirilmiş mine yüzeylerine fissür örtücülerin uygulanması sonucu bağlanma kuvvetleri değerlerinin, fosforik asit ile pürüzlendirilmiş mine yüzeylerinde fissür örtücülerin bağlanma değerlerinden daha düşük olduğunu bulmuşlar (Güven ve ark 2010).

Karaman ve ark (2012) Er, Cr: YSGG veya asitle pürüzlendirme ile fissür örtücülerin 18 aylık performanslarını değerlendirdiği çalışmada, Er, Cr: YSGG uygulanan fissür örtücülerin, asit uygulananlara göre retansiyonlarının düşük olduğunu fakat istatistiksel olarak anlamlı fark oluşturmadığını bildirmişlerdir. Araştırmacılar fissür örtücü uygulamalarında Er:YAG lazer kullanılmasının asit intiyacını elimine etmediğini savunmuşlardır. Borsatto ve ark (2004) ise lazer ve asit uygulamalarının fissür örtücü-mine arasında mikrosızıntıya etkisini araştırdıkları çalışmada lazer uygulanan yüzeylerde mikrosızıntının asit uygulananlara göre daha fazla olduğu sonucuna varmışlardır.

Er: YAG lazer ile mine yüzeyi pürüzlendirmesinde atış süresi ve enerji parametreleri lazer ablasyonunun gerçekleştirilmesinde hayati öneme sahiptir. Lazer uygulaması esnasında pulpal yüzeyde ısı birikimini azaltmak ve saçılma etkisini azaltmak için Er: YAG lazerin kullanımında kısa süreli ve enerji seviyesi düşük atış seviyesine sahip modlar kullanılmalıdır (Sağır ve ark 2013).Bu amaçla QSP modu geliştirilmiştir. Bu çalışmada Er:YAG lazerin MSP modunun yanısıra yeni geliştirilen QSP teknolojisi kullanılarak mineye fissür örtücünün bağlantısına etkisi değerlendirilmiştir.

Çalışmamızın sonucunda Er: YAG lazer QSP ve MSP modu ile pürüzlendirilmiş mine yüzeylerinde fissür örtücülerin bağlantısı asit uygulanan grubun bağlantısından daha düşük bulunmuştur. Bu sonuç; Lepri ve ark (2008) çalışmaları ile benzerlik göstermektedir. Çalışmamızın sonuçlarına göre lazerin farklı modlarda uygulamasının asit intiyacını ortadan kaldırmadığını söyleyebiliriz.

Sağır ve ark (2013) tarafından ortodontik braketlerin Er: YAG lazerin farklı modları kullanılarak mine yüzeyine bağlantısının karşılaştııılığı çalışmada Er: YAG lazer QSP modunun kullanıldığı grubun bağlanma değerleri, fosforik asit ile mine yüzey hazırlığı yapılan grubun bağlanma değerlerinden daha yüksek olduğu bulunmuştur. QSP modu kullanılan grup ile MSP modu kullanılan grup arasında istatistiksel olarak anlamlı fark bulunmamıştır. Yaptığımız çalışmanın sonucu bu çalışmanın sonuçları farklıık göstermektedir. Bu farklılığın sebebi lazer uygulaması esnasında yüzeyde oluşturulan pürüzlendirmenin, minenin her yerinde aynı miktar ve özellikte gerçekleşmemiş olmasından kaynaklanmış olabilir. Özellikle fissür örtücülerin mineye bağlantısını artırmak için lazer uygulanan çalışmalarda asit uygulamasının daha yüksek bağlanma dayanımına neden olması araştırmacılar tarafından lazerin mine yüzeyinde homojen, uniform mikropöröziteler oluşturamamasına bağlanmıştır (Siverstone 1983, Bevilacqua et al 2008, Lepri et al 2008). Buna ilave olarak, lazer ışınının sürekli olmayan yayılımı sonucunda lazer ışını almamış yüzeylerin ortaya çıkabileceği iddia edilmiştir (Aper et al 2002). Bu şekilde oluşan düzensiz mikropörözitelerin de bağlanma dayanımını zayıflatabileceği bildirilmiştir (Chimello-Sousa et al 2006).

Kurutma ajanları nemli mine yüzeyine fissür örtücülerin daha iyi penetre olmalarına olanak sağlamak amacıyla geliştirilmişlerdir. Adams ve ark (2000) yaptıkları çalışmalarında kurutma ajanı kullanıldığında fissür örtücünün daha iyi penetre olduğu sonucuna varmışlardır. Çalışmamızın sonuçları incelendiğinde kurutma ajanı uygulaması bağlanma dayanımını, genellikle artırmakla birlikte, kurutma ajanı uygulanan ve uygulanmayan gruplar arasında istatistiksel fark olmadığı görülmektedir. Ayrıca fissür örtücü uygulama aşamasında basamak sayısını artırması, özellikle çocuk hastalarda, koltukta oturma zamanının uzamasına neden olacağından bir dezavantaj olarak karşımıza çıkmaktadır.

\section{SONUÇ}

Mine yüzeyine Er: YAG lazer QSP ve MSP uygulamalarının bağlanma dayanım değerleri, fosforik asit uygulamasından daha düşük bulunmuştur.

Fissür örtücülerin bağlanma dayanımını artırmak için asit uygulanmasına ilave olarak kurutma ajanı, hekimin tercihine bağlı olarak uygulanabilir.

Ayrıca mine yüzeyi pürüzlendirmesinde lazer sistemlerin geliştirilmesi gerektiği ve yeniliklere paralel olarak daha çok çalışmaya intiyaç duyulduğu görülmüştür. 


\section{Farklı yüzey hazırlama yöntemlerinin fissür} örtücülerin bağlanma dayanımı üzerine olan etkisi

Amaç: Bu çalışmada amacı kurutma ajanı/ kurutma ajanı olmaksızın mine yüzeyinin hazırlanmasında asitle pürüzlendirme ve Er:YAG lazerin (QSP ve MSP mod) fissür örtücünün bağlanma dayanımı üzerine etkisini değerlendirmek amaçlandı.

Gereç ve Yöntemler: Bu çalışmada 30 adet çürüksüz daimi diş kullanıldı. Dişler mine-sement sınırının $2 \mathrm{~mm}$ üstünden kesildi ve kökler uzaklaştıııldı. Dişler meziodistal olarak ikiye ayrıldı. Elde edilen 60 yarım diş akrilik reçine içine gömüldü. Mine yüzeyinde fissure örtücüler için 2 $\mathrm{mm}$ çapında alan oluşturuldu. Bütün gruplara Ultraseal XT plus (Fissür örtücü:FÖ) uygulandı. Örnekler randomize olarak 6 gruba ayrıldı (n:10); G1:\% 37 fosforik asit + Prima Dry + FÖ, G2:\% 37 fosforik asit + FÖ, G3: Er: YAG (MSP modu) + Prima Dry + FÖ; G4: Er: YAG (MSP modu) + FÖ; G5: Er: YAG (QSP modu) + Prima Dry + FÖ; G6: Er: YAG (QSP modu) + FÖ. Örnekler 24 saat distile su içinde bekletildikten sonra bağlanma kuvvetleri, üniversal test makinesi ile test edildi. Verileri karşılaştırmak için Kruskal-Wallis ve Mann-Whitney U-testi kullanıldı.

Bulgular: Gruplara ait bağlanma dayanımları şöyledir (MPa) G1: 11.33, G2: 9.76, G3: 8.65, G4: 7.72, G5: 4.49, G6: 2.73. Gruplar arasında istatistiksel fark olduğu gözlendi $(p<0.05)$.

Sonuç: Mine yüzeyine asit uygulaması, Er:YAG lazer QSP ve MSP moda göre daha iyi sonuçlar verdiği görülmüştür. Fissür örtücü uygulanmadan önce kurutma ajanı uygulanabilir.

\section{ANAHTAR KELIMELER}

Asit, fissür örtücü, lazer QSP

\section{KAYNAKLAR}

Adams TJ, Frazier KB, Browning WD, 2000. Effect of drying agent use on sealant penetration. Journal of Dental Research, 79: 189 (Abstr. 363).

Apel C, Franzen R, Meister J, et al 2002. Influence of the pulse duration of an Er:YAG laser system on the ablation threshold of dental enamel. Lasers Med Sci 17(4):253-257.

Bevilacqua FM, Zezell DM, Magnani R, et al 2008. Fluoride uptake and acid resistance of enamel irradiated with Er:YAG laser. Lasers Med Sci 23(2):141-147.
Boksman L, Carson B, 1998. Two-year retention and caries rates of UltraSeal XT and Fluorshield light cured pit and fissure sealants. General Dentistry 46, 184-187.

Borsatto MC, Corona SA, Ramos RP, Liporaci JL, Pecora JD, Palma-Dibb RG, 2004. Microleakage at sealant/ enamel interface of primary teeth: Effect of Er:YAG laser ablation of pit and fissures. J Dent Child (Chic), 71,143-7.

Buonocore MG, 1955. A simple method of Increasing the adhesion of acrylic filling materials to enamel surfaces. J Dent Res, 34, 849-53.

Chimello-Sousa DT, de Souza AE, Chinelatti MA, et al 2006. Influence of Er:YAG laser irradiation distance on the bond strength of a restorative system to enamel. J Dent 34(3):245-251

Grgurevic J, Grgurevic L, Miletic I, Karlovic Z, Jukic Krmek S, Anic I, 2005. In vitro study of the variable square pulse Er:YAG laser cutting efficacy for apicectomy. Lasers Surg Med. 5, 347-350.

Gutknecht N, Lukac M, Marincek M, Perhavec T, Kazic M, 2011. A novel quantum square pulse (QSP) mıde erbium dental laser. J LAHA, 1, 15-21.

Güven Y, Çömlekçi H, Aktören O, 2010. Assessment of the effect of ER:YAG laser conditioning on bond strength of fissure sealants. İstanbul Üniv Diş Hek Fak Derg, 44(1), 1-6.

Karaman E, Yazıcı R, Görücü J, Başeren M, 2012. 18-month clinical performance of fissure sealants applied with different etching methods. GÜ Diş Hek Fak Derg 29(1), 33-40.

Koch G, Poulsen S, Twetman S, 2001. Caries prevention in child dental care. In: Koch G, Poulsen $S$ (eds). Pediatric Dentistry: A Clinical Approach. Copenhagen: Munks-gaard, 2001: 119-45.

Lepri TP, Souza-Gabriel AE, Atoui JA, Palma-Dibb RG, Pécora JD, Milori Corona SA, 2008. Shear bond strength of a sealant to contaminated-enamel surface: influence of erbium: yttrium-aluminumgarnet laser pretreatment. J Esthet Restor Dent, 20(6), 386-92.

Lukac M, Primc NM, Pirnat S, 2012. Quantum square pulse Er:YAG lasers for fast and precise hard dental tissue preparation. J LAHA, 1, 14-21.

Mironow E, 2012. Clinical Experience with a Quantum Square Pulse (QSP) Er:YAG Laser.

Sağır S, Usumez A, Ademci E, Usumez S, 2013. Effect of enamel laser irradiation at different pulse settings on shear bond strength of orthodontic brackets. Angle Orthod, 83(6), 973-80. 
Silverstone LM 1983. Fissure sealants: the enamelresin interface. J Public Health Dent 43(3):205-215 .

Splieth $\mathrm{CH}$, Ekstrand KR, Alkilzy $\mathrm{M}$, et al, 2010. Sealants in dentistry: outcomes of the ORCA Saturday Afternoon Symposium 2007. Caries Res, 44, 3-13.

Waggoner WF, Siegal M,1996. Pit and fissure sealant application: updating the technique. J Am Dent Assoc, 127(3), 351-61.

Weintraub JA, 1989. The effectiveness of pit and fissure sealants. J Public Health Dent. 49 (5), 317330.

Yazışma Adresi:

Gül TOSUN

Selçuk Üniversitesi Diş Hekimliği Fakültesi

Pedodonti AD

42078 Selçuklu, Konya

Tel : +90 3322231290

Faks: +90 3322410062

E-mail: gultosun@hotmail.com 